2000

\title{
Asymmetries of Brain Function in Alcoholism: Relationship to Aging
}

Oscar Berman, M

http://hdl.handle.net/10026.1/1203

Kluwer Academic Pub

All content in PEARL is protected by copyright law. Author manuscripts are made available in accordance with publisher policies. Please cite only the published version using the details provided on the item record or document. In the absence of an open licence (e.g. Creative Commons), permissions for further reuse of content should be sought from the publisher or author. 


\title{
NEUROBEHAVIOR OF LANGUAGE AND COGNITION
}

Studies of Normal Aging and Brain Damage Honoring Martin L. Albert

\author{
EDITED BY \\ LISA TABOR CONNOR \\ LORAINE K. OBLER
}

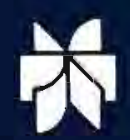

KLUWER ACADEMIC PUBLISHERS 


\title{
ASYMMETRIES OF BRAIN FUNCTION IN ALCOHOLISM: RELATIONSHIP TO AGING
}

\author{
Marlene Oscar-Berman and Haline E. Schendan
}

\section{INTRODUCTION}

Alcohol-related brain impairment has been associated with a variety of behavioral changes, indicating deficits in perceptual, emotional, and other cognitive functions. The present report reviews recent accomplishments in cognitive neuroscientific research on asymmetries of cerebral functioning that may be altered as a residual consequence of long-term chronic alcoholism. Residual effects - in contrast to acute effects - can be studied only in people who have abused alcohol for a lengthy period of time but who have been sober for at least four weeks prior to testing. In addition, they must be free of other comorbid medical complications that can affect brain functioning. Comorbid conditions (e.g., head injury, history of abuse of other drugs, concurrent psychiatric diagnoses, liver disease, HIV infection, etc.) are exclusionary criteria because cormorbidities may contribute to artifactual results that complicate interpretation.

Not all alcoholics are equally at risk for brain changes and neuropsychological deficits. The locus and extent of brain damage, as well as the type and degree of impairment, differ across individuals. These differences suggest that (a) certain subgroups of people (e.g., the elderly and women) are especially vulnerable to the neurotoxic sequelae of alcoholism, (b) that the susceptibility of particular brain regions (e.g., cerebral cortex and limbic and diencephalic structures) to alcoholismrelated damage varies among individuals (e.g., with age and gender). To account for the diversity of findings, researchers have proposed different models. For context, Table 1 lists common current theoretical frameworks proposed to explain the residual neuropsychological impairments in abstinent long-term alcoholics. The models tend to focus on the vulnerability of particular participant populations, brain regions, or cognitive functions, but these factors are related. In this chapter, our discussion focuses upon the influence of alcoholism on the functioning of the cerebral hemispheres, particularly in relation to increased vulnerability associated with aging. Toward this end, our review covers primarily recent research on alcoholism and aging, as well as relevant cognitive neuroscience findings with nonalcoholic populations. 


\section{RIGHT-HEMISPHERE FUNCTIONS AND ALCOHOLISM}

Clinical reports and experimental studies have provided evidence that each hemisphere of the human brain is important for mediating different functions. The left hemisphere of the brain has a dominant role in communication and in understanding the spoken and written word, while the right hemisphere plays a dominant role in coordinating interactions with the three dimensional world around us (e.g., spatial cognition). Processing modes of the two hemispheres also complement each other, depending upon context and task demands (Banich \& Heller, 1998). The left hemisphere plays a special role in processing piecemeal information analytically and sequentially, and the right hemisphere plays a special role in integrating information holistically. Differences between the two cerebral hemispheres can be seen easily in cases of unilateral brain damage, and standard clinical neuropsychological tests are helpful for educing this dichotomy (e.g., see Lezak, 1995). Patients with left-hemispheric damage often have problems with language, and patients with right-hemispheric damage often have difficulty with maps, designs, music, and other nonlinguistic materials. Of interest to the present discussion is the fact that alcoholic and aging individuals have difficulty on tasks that resemble those on which patients with damage to the right hemisphere also encounter problems. In particular, patients with right-hemisphere lesions, as well as alcoholic and elderly individuals, are disproportionately impaired on nonverbal visuospatial tasks, as assessed by Performance IQ subtests (compared with Verbal IQ subtests) of the Wechsler Adult Intelligence Scale (WAIS) (Wechsler, 1981).

These observations led, independently, to the right-hemisphere hypothesis in both the alcoholism literature and the aging literature (Parsons, 1987). The righthemisphere hypothesis states simply that the right half of the brain is more vulnerable to the effects of alcoholism (or the effects of aging) than the left half of the brain. In other words, a disproportionate decline in visuospatial and other nonlinguistic functions has been attributed to a greater sensitivity of the right hemisphere to the neurobiological consequences of alcoholism or aging. Later research on right-hemisphere contributions to cognitive (e.g., spatial and attentional) functions in alcoholism and aging has provided only equivocal support for the hypothesis that alcoholism and aging - alone or together - differentially affect the functioning of the two cerebral hemispheres (Bates \& Convit, in press; Ellis \& Oscar-Bermanl, 1989; Oscar-Berman, 1992; Parsons \& Nixon, 1993; Rourke \& Løberg, 1996).

\section{ALCOHOLISM AND AGING}

Neuropathological analyses provided some of the earliest insights into the relationship between alcoholism and aging. In post mortem specimens of alcoholic brains, cerebral atrophy was noted to resemble the brain shrinkage that occurs with normal chronological aging (Courville, 1966). The atrophy was most prominent is the frontal lobes, and it extended backwards to the parietal lobes. This finding was replicated by others who reported abnormal ventricular enlargement and widenivg 
of the cerebral sulci of alcoholics in relation to increasing age (Pfefferbaum et al., 1993). From the observed similarities among the brains of alcoholic and aging individuals came a search for parallels in functional decline associated with alcoholism and aging.

\begin{tabular}{|l|}
\hline \multicolumn{2}{|c|}{ MODELS EMPHASIZING VULNERABILITY IN TERMS } \\
OF SUBJECT VARIABLES
\end{tabular}

\section{Gender}

Alcoholism affects women more than men.

\section{Vitamin Deficiency}

Thiamine deficiency contributes to brain lesions, especially in patients with Wernicke-Korsakoff's syndrome.

\section{MODELS EMPHASIZING VULNERABILITY OF BRAIN REGIONS/SYSTEMS OR FUNCTIONAL PROCESSES}

\section{Diffuse Cortical Atrophy}

Cerebral atrophy occurs throughout the brain.

\section{Right-hemispheric Functions}

Are more vulnerable to the effects of alcoholism than are left-hemispheric functions. (The same hypothesis has been applied to normal chronological aging, hence, more fuel for the premature aging hypothesis.)

\section{Frontal Lobe Systems}

Are more vulnerable to the effects of alcoholism than other cortical systems.

\section{Limbic and Diencephalic Brain Regions}

Are vulnerable to the effects of alcoholism in Korsakoff's syndrome.

\section{Neurotransmitter Systems}

Emphasis is placed on the disruption of neurotransmitter systems, such as acetylcholine, dopamine, GABA, glutamate, and serotonin systems.

\section{Reduction in Efficiency of Mental Operations}

Emphasis is placed on impairments of underlying cognitive processes.

Tabie 1. Models proposed to explain the neuropsychological consequences of alcohol-related brain damage. The hypotheses are not mutually exclusive; some are interrelated. There are supporting data for these hypotheses from neurobehavioral studies, brain scans, electrophysiological studies, and post mortem neuropathology. 
The premature aging hypothesis has been put forth in two versions (reviewed by Ellis \& Oscar-Berman, 1989). According to the first version, the accelerated aging (or cumulative effects) model, alcoholism is accompanied by the precocious onset of neurobiological and behavioral changes typically associated with advancing age. Cognitively, or neuropsychologically, alcoholics become old before their time. This version proposes that alcoholics at all ages are impaired compared to age-matched nonalcoholics.

The second version places the timing of the changes somewhat differently. In this view, which has been labeled the increased vulnerability model, the aging brain is more vulnerable to the deleterious influences of toxic substances, including ethanol, than is the brain of a younger person. Therefore, the cognitive decline associated with normal chronological aging (beginning at around age 50) receives added momentum when combined with alcoholism. This version proposes that older alcoholics are impaired compared to age-matched nonalcoholics; however, this would not be the case for younger alcoholics.

\section{EMPIRICAL INVESTIGATIONS}

\section{Neuropathology, Neuroimaging, and Neurobehavior}

Taken together, most of the evidence from neuropathological and neuroradiological investigations indicates that there is a link between alcoholism and premature aging (Oscar-Berman, 1998; Sullivan, Rosenbloom, \& Pfefferbaum, 1998). Furthermore, studies favoring the increased vulnerability model are more common than those supporting the accelerated aging model (Oscar-Berman, 1998) although results of one recent study favor the latter. Belzunegui, Insausi, Ibanez and Gonzalo (1995) examined the neuronal nuclear size and the neuronal population of the mammillary bodies and anterior thalamic complex in alcoholics and cortroil of ages 30 to 75 . These subcortical structures are of particular interest becars lesions to them are thought to be critical for establishing the memory impairment in alcoholic Korsakoff's amnesia (for review see Kopelman, 1995). Belzunegui tt al (1995) found significant reductions in neuronal size and number in the alcoholic but the youngest alcoholics showed the greatest differences.

Most data, however, support the idea that older alcoholics are especialth susceptible to the effects of alcoholism. Elderly alcoholics have an increased risk of accidents, side effects, and toxicity resulting from alcohol intake. This is becsus older people have a decreased ability to metabolize alcohol, and they may har concomitant medical problems (NIAAA, 1997). As predicted by the increas vulnerability model, certain brain structures show greater reduction in size in olde alcoholics than in younger alcoholics. These are the cerebral cortex (Nicolás etal. 1997; Pfefferbaum, Sullivan, Mathalon, \& Lim, 1997), the hippocampus (but \& Harding, Wong, Svoboda, Kril, \& Halliday, 1997; Sullivan, Marsh, Mathalon, lin \& Pfefferbaum, 1995), and the cerebellum (Sullivan et al., 1996; for review s: Sullivan et al., 1998). Alcoholics also have shown a stronger association betw: ventricular dilation and age compared with nonalcoholic controls (Di SclafanietL. 1995). 
More important for the issue of neurobehavioral hemispheric asymmetries in alcoholism and aging, the callosal area is notably reduced with age in alcoholics (Pfefferbaum, Lim, Desmond, \& Sullivan, 1996); the corpus callosum enables communication between the cerebral hemispheres. Abnormalities in the structure of the corpus callosum can occur as a consequence of diffuse cortical damage and subsequent degeneration of cortical axons. Diffuse cortical damage, in turn, would be interpreted in conventional neuropsychological testing as a selective righthemisphere functional deficit either because right-hemisphere functions have less cortical representation than left-hemisphere functions or because nonverbal tasks tend to be more difficult or less familiar than verbal tasks (Ellis \& Oscar-Berman, 1989). Alternatively, diffuse cortical and/or callosal atrophy could interfere with cross-callosal transfer of information, causing some of the cognitive deficits observed in alcoholics and aging individuals (Hutner \& Oscar Berman, 1996; Rourke \& Løberg, 1996). For example, if the left hemisphere's contribution to nonverbal tasks normally is greater than the right hemisphere's contribution to verbal tasks, an interhemispheric transfer dysfunction would affect visuospatial functions more than verbal functions. Because the characteristics of hemispheric dominance are specific to each functional brain area, the altered patterns of hemispheric dominance from alcoholism and aging may be idiosyncratic to those brain areas and behavioral functions. It is, therefore, important to appreciate which brain regions are affected by chronic alcoholism and aging.

Cortical changes have been reported throughout the brain, but there is evidence that some cortical regions, especially the frontal and parietal lobes, are more consistently vulnerable to the effects of chronic alcoholism, as well as aging (Adams et al., 1998; Davila, Shear, Lane, Sullivan, \& Pfefferbaum, 1994; Estruch et al., 1997; Kril, Halliday, Svoboda, \& Cartwright, 1997; Pfefferbaum \& Rosenbloom, 1993; Shear, Sullivan, Lane, \& Pfefferbaum, 1996; Sullivan et al., 1995; Wang et al., 1993). Frontal, cingulate, parietal, parieto-occipital, and mesial temporal cortices in alcoholics show reduced metabolic activity with positron emission tomography (PET) (e.g., Adams et al., 1993; Gilman et al., 1996; Volkow et al., 1995; Volkow et al., 1997) and significantly smaller gray and/or white matter volume with structural magnetic resonance imaging (MRI) (e.g., Jernigan et al., 1991; Sullivan, Mathalon, Lim, Marsh, \& Pfefferbaum, 1998). Selective neuronal loss in the frontal lobes has also been observed at a microscopic level (e.g., Kril et al., 1997). Additionally, Pfefferbaum, Sullivan, Mathalon, and Lim (1997) conducted a regional MRI analyses of cortical integrity and found evidence that cortical volume loss in alcoholism and aging is selective. The frontal lobes were especially vulnerable to chronic alcoholism at any age, but the effects were exacerbated in elderly people; temporal-parietal loss occurred mainly in aged alcoholics. These results favor the increased vulnerability model of premature aging in alcoholism. Another recent study by Sullivan et al. (1998) showed fewer regional abnormalities, but the investigators did note a relative sparing of gray matter (but loss of white matter) in the posterior superior temporal region that was also noted in the Pfefferbaum et al. (1997) study.

Neurobehavioral findings also tend to support the view that aging increases one's vulnerability to alcohol-related decline, but controversy prevails (see review by Evert \& Oscar-Berman, 1995). With behavioral measures, the association 
between alcoholism and aging is less reliable than with imaging techniques. More importantly, when neurobiological and behavioral changes are examined together in the same study, concomitant brain damage with performance impairments are not always found.

Some studies of frontal lobe function with older alcoholics have confirmed reports of a correlation between impaired neuropsychological performance on tests of frontal functioning (e.g., executive control skills) and decreased frontal lobe perfusion or metabolism (Adams et al., 1998; 1993). However, in another study, Nicolás, Catafau, Estruch, Lomeña, Salamero, Herranz, Monforte, Cardenal, and Urbano-Marquez (1993) obtained cerebral blood flow measures and computerized tomography (CT) scans in a sample of 40 chronic alcoholic patients and related the neuroradiological findings to the results of neuropsychological testing. The researchers found evidence of significant brain hypoperfusion in the alcoholics. In 26 of the 40 , the reduced blood flow was mainly in the frontal lobes, but only about $25 \%$ of them ( 11 of the 40 ) had CT evidence of frontal atrophy. Furthermore, the alcoholics exhibited significant impairments on tests of frontal-lobe functioning and visuospatial skills. Despite finding brain and behavioral changes, there was an independent relationship between frontal-lobe test performance and both frontal atrophy and frontal hypoperfusion. Age was not a relevant variable in this study.

In a study of other neural structures, Sullivan and her colleagues (1995) reported clear evidence of brain abnormalities but no differences on explicit memory tests in alcoholics relative to nonalcoholic controls aged 21 to 70 years Explicit memory refers to the ability to consciously remember facts and events. It is assessed by recognition and recall tests and is impaired in alcoholic Korsakoff and other amnesic patients (for recent reviews see Kopelman, 1995; Mayes, 1995). The hippocampus and adjacent cortical areas have been strongly implicated in explicit memory by a host of neuropsychological, brain imaging, and nonhuman animal studies (for recent review see Eichenbaum, 1997). Sullivan et al. (1995) evaluated whether there were correlations between MRI measures of hippocampal volume and behavioral measures of verbal and nonverbal delayed recall, as defined by the Wechsler Memory Scale (WMS) (Wechsler \& Stone, 1945). Anterior portions of the hippocampus were found to be smaller in the alcoholics than in the controls, and this difference was even greater in older than in younger alcoholics. While the MRI findings support the increased vulnerability model, the behavioral significance of the neuroanatomical reduction (i.e., increased hippocampal vulnerability in aging and alcoholism) was unclear because the explicit memory scores did not correlate with hippocampal volumes. Indeed, the alcoholics were not impaired on the memory tests. Furthermore, contrary to the right-hemisphere hypothesis, hippocampal reductions were bilateral, and verbal and nonverbal explicit memory performance did not differ. Sullivan et al. (1995) did, nonctheless, observe the of reported visuospatial impairments on the WAIS-R Digit Symbol subtest. While tis subtest has a memory component, there were also no correlations between Digt Symbol performance and hippocampal volume.

Another study found no evidence of cortical atrophy but did show aging: related cognitive deficits. Di Sclafani et al. (1995) scanned older alcoholics and controls using MRI and gave them numerous neuropsychological tests in order to 
compare brain measures with cognitive abilities. The alcoholics displayed clear impairments on visuospatial and memory tasks, especially visuospatial memory. Despite the behavioral deficits, there were no group differences in global cerebral atrophy (although two alcoholics had significant atrophy). One reason for cognitive dysfunction in the absence of changes in gross brain morphology is that there can be synaptic neuronal changes that alter processing but are undetectable at a macroscopic anatomical scale (for recent review see Harper, 1998). Di Sclafani et al. (1995), however, did find a stronger association between ventricular dilation and age in the alcoholics than in the controls.

\section{INTERMANUAL DIFFERENCES AND LATERALIZED SENSORY PRESENTATION}

The efficacy of the measuring instruments for assessing cognitive functions hemispheric laterality in particular - is critical. Tasks where distinct stimuli are presented either simultaneously or asynchronously to sense organs on one or the other side of the body, or that require separate responses by the left or right hands, are important tools for assessing hemispheric asymmetries (for review see Ellis \& Oscar-Berman, 1989). In such tasks, stimuli are processed (and motor responses are made) by neural events controlled mainly by the cerebral hemisphere contralateral to the side of sensory input (or response effector). Because of the decussation (crossing) of neuronal transmission fibers within the central nervous system, stimuli presented to the sensory field on one side of the body (e.g., the Left Visual Field [VF]) proceed first to the opposite side of the brain (i.e., the right hemisphere) before crossing over to the other side of the brain. Similarly, motor responses are made by the limb opposite to the hemisphere of interest (e.g., the left hand is controlled by the right hemisphere).

From these organizational principles comes a relatively straightforward test of the right-hemisphere hypothesis of alcoholism; that is, to contrast performance of each hand. Since there is asymmetric cerebral dominance of motor control, performance should be better for the preferred over the nonpreferred hand. In the case where the preferred hand is disproportionately better than the nonpreferred hand, this may be taken as evidence for damage to the nondominant hemisphere controlling the nonpreferred hand. Specifically, for right-handed people (i.e., lefthemisphere dominant), alcoholics should perform disproportionately better than nonalcoholic controls with their right hand than their nonpreferred left hand (controlled by the right hemisphere), according to the right-hemisphere hypothesis.

There are several reports of disproportionate impairment of alcoholics when they use their left hands (i.e., right hemisphere) compared to controls (for a review see Ellis \& Oscar-Berman, 1989), particularly on the Tactual Performance Test (TPT) of the Halstead-Reitan Neuropsychological Test Battery (Reitan \& Davison, 1974). It would thus seem that right-hemisphere control of motor behavior may be especially vulnerable to alcoholism. In a recent study, however, this possibility was evaluated in a relatively large sample of long-term, abstinent alcoholics and nonalcoholic controls (mean ages 42 years and 46 years, respectively). Participants performed several subtests of the Halstead-Reitan Battery with each hand separately. Contrary to the right-hemisphere account of alcoholism, there were no 
differences in handedness patterns between alcoholics and controls on any of the tasks, even the TPT (Kwon, Rourke, \& Grant, 1997).

As with the motor end of behavior, research using lateralized sensory presentation also has provided conflicting evidence for the right-hemisphere hypothesis, as well as for the premature aging model of alcoholism (see reviews by Ellis \& Oscar-Berman, 1989; Oscar-Berman, 1992; Parsons \& Nixon, 1993). For example, Ellis (1990) used a dichotic listening technique to measure hemispheric asymmetries for perceiving two types of stimuli presented simultaneously to the two ears: linguistic (words) and musical (strings of piano notes). In most people, word perception is accomplished principally by the left hemisphere, whereas musical perception is accomplished principally by the right hemisphere (Lezak, 1995). Therefore, with linguistic stimuli, accuracy for words heard by the right ear would normally be greater than when heard by the left ear, whereas, with musical patterns, accuracy for notes heard by the left ear would normally be greater than when heard by the right ear. The main subject groups in the Ellis (1990) study were abstinent alcoholics and nonalcoholic controls (from ages of 25 years and 74 years). However, it is important that Ellis (1990) also included a group of nonalcoholic stroke patients with focal lesions in the right hemisphere. The focal lesion group served to establish performance baselines that result from confirmed damage to the right hemisphere (for comparison with the predicted right-hemisphere dysfunction in the alcoholics).

The right-hemisphere stroke patients showed a general rightward shift, that is, they showed a magnified superiority of the right ear (left hemisphere) for words but also an atypical right ear advantage for the tones. This abnormal pattern did not emerge with the other groups, however. The alcoholics and age equivalent controls performed similarly, whether the stimuli were linguistic or musical; specifically, alcoholics and nonalcoholic controls of all ages obtained typical right ear advantages for words and typical left ear advantages for tonal patterns. Despite the normal performance on dichotic listening by the alcoholics, on Performance subtests of the WAIS-R, Ellis (1990) found that the right-hemisphere stroke patients and the older alcoholics (ages 48 years to 74 years) but not the younger alcoholics (ages 25 years to 47 years) performed significantly worse than same age nonalcoholic controls. In other words, like the right-hemisphere stroke patients, the older alcoholics showed an abnormal Verbal-Performance WAIS-R IQ discrepancy. Thus, the results of the dichotic listening experiments did not support any of the hypotheses, whereas the neuropsychological findings with the same participants were supportive of the right-hemisphere hypothesis of both alcoholism and of aging, in particular the increased vulnerability model.

\section{SPATIAL COGNITION}

As just noted, Performance subtests of the WAIS, such as Digit Symbol and Block Design, have been sensitive to the cognitive changes associated with alcoholism and normal chronological aging (Ellis \& Oscar-Berman, 1989; Kaplan, 1988). While the Digit Symbol and Block Design subtests are considered to provide measures of visuospatial function and right-hemisphere integrity, 
performance on the subtests depends upon many diverse functional capacities and many brain areas. Functions tapped include: processing-speed/accuracy, motorspeed/accuracy, working memory, paired associate learning, visual perception, spatial cognition, attention, and visual scanning ability (Wechsler, 1997). Each of these cognitive abilities, in turn, engages multiple brain areas. By tapping diverse functions, clinical neuropsychological tests carry the advantage of exquisite sensitivity to brain injury. By virtue of their sensitivity, the subtests have been useful for demonstrating diminished cognitive abilities in a variety of neurological populations, including alcoholics (Beatty, Blanco, Hames, \& Nixon, 1997; for recent research see Beatty, Hames, Blanco, Nixon, \& Tivis, 1996; Ciesielski, Waldorf, \& Jung, 1995; Di Sclafani et al., 1995; for review see Milberg, Hebben, \& Kaplan, 1996). Their sensitivity also diminishes the utility of the subtests toward defining the integrity of focal brain areas. Their lack of specificity is partly responsible for the elusive nature of consistent findings of cognitive compromise in alcoholism. Indeed, normal standardized scores have been achieved by alcoholics (e.g., Beatty, Katzung, Moreland, \& Nixon, 1995; Kwon et al., 1997; Volkow et al., 1997) as well as by focal lesion patients (see review by Kaplan, 1988; Kaplan, Palmer, Weinstein, \& Baker, 1981).

The sensitivity of clinical neuropsychological tests to brain injury does, nonetheless, make them potentially useful, especially when they supplement studies employing experimental cognitive tasks. Besides providing broad indications of cognitive deficits, when different laboratories use the same neuropsychological assessment procedures comparisons among studies are facilitated. Further, neuropsychological tests can help address whether, for example, the sample size was sufficiently large or the selected population was sufficiently uniform to detect differences among alcoholic and control groups. This is especially important in cases where experimental tests do not show group differences. A Process approach to neuropsychological assessment is helpful in this regard (as described by Milberg et al., 1996).

\section{PROCESS APPROACH}

Measurements from neuropsychological tests administered in a processoriented manner not only have the advantage of sensitivity, as for any neuropsychological test, but they have the added advantage of greater specificity regarding cognitive impairments and locus of damage (Kaplan, 1988). This is accomplished by altering the administration or response recording procedures to enable a wide spectrum of measurements to be derived from each clinical test. The Process approach is akin to the extra measurements taken and further data permutations carried out in experimental research.

A process-oriented neuropsychological assessment was combined with administration of experimental tasks in an exemplary study by Beatty, Hames, Blanco, Nixon, and Tivis (1996), and to some extent, also by Beatty, Blanco, Hames, and Nixon (1997). The aim of the Beatty et al. (1996) study was to use competing models of spatial information processing to test theories of spatial impairment in alcoholism. The three models conceptualized spatial ability as focused upon: (1) egocentric (self as reference; frontal lobe) versus allocentric 
space (object located with reference to another object; right parietal lobe); (2) categorical (relative positions of features to each other; left hemisphere) versus coordinate spatial representation (absolute distance between features; right hemisphere); or (3) featural (local level; left hemisphere) versus configural analysis (global configuration; right hemisphere), with the last applied often to understanding processing of hierarchical visual objects (see later section on this topic). Accordingly, Beatty et al. (1996) noted that the right-hemisphere hypothesis would predict marked impairments by alcoholics on visuospatial tasks engaging coordinate and configural brain functions; note, while not mentioned as such by the authors, the right parietal lobe's role in allocating attention to allocentric space suggests that allocentric tasks may also provide an appropriate test of righthemisphere functioning. By contrast, a model that posits diffuse bilateral damage (e.g., in frontal or limbic systems) (see Table 1 and Rourke \& Løberg, 1996) would predict measurable impairments on visuospatial tasks engaging egocentric functions and, possibly, on frontal lobe components of categorical and featural tasks as well. Beatty et al.'s results, however, were inconsistent with both accounts of alcoholismrelated brain damage.

Beatty et al. (1997; 1996) tested young male and female alcoholics and controls (mean ages 40 years and under) on numerous tasks that were each designed to assess aspects of spatial abilities (Beatty et al., 1997; Beatty et al., 1996). Beatty and his colleagues evaluated the featural versus configural analytical model with clinical neuropsychological tests. The alcoholics attained lower scores on both the Block Design and Object Assembly subtests of the WAIS-R. More importantly, because these subtests were administered and scored with the process-oriented approach of the WAIS-RNI (Kaplan, Fein, Morris, \& Delis, 1991), they also yielded more data relevant to the question of asymmetries of featural analysis (left hemisphere) and configural analysis (right hemisphere). Specifically, the processoriented analysis of Block Design performance showed that alcoholics made more configural errors; that is, the error type found in patients with right- but not lefthemisphere lesions (Kaplan et al., 1981). This was not, however, the case for performance on the additional Object Assembly puzzles advocated by the Process approach. The speed of puzzle completion and pattern of impaired performance by alcoholics (Beatty et al., 1997; Beatty et al,, 1996) most closely resembled those found in patients with left-hemisphere lesions (Kaplan, 1988). This then suggests an alcoholic impairment in featural processing. Taken together, the Block Design and Object Assembly results did not support the right-hemisphere hypothesis. Instead, because damage in one or the other hemisphere may dominate performance in different tasks, the finding that alcoholics were impaired at both featural and configural analyses was suggestive of bilateral damage.

The other models were evaluated by Beatty et al. $(1997 ; 1996)$ using experimental tests alone (categorical versus coordinate) or both neuropsychological and experimental tests (egocentric versus allocentric). Aicoholics were impaired on the test of categorical but not coordinate relations, and they were indistinguishable from controls on remote memory for the same information, contrary to the righthemisphere hypothesis. Alcoholics performed normally on the egocentric task (a clinical test) and on one out of three allocentric tasks (clinical and experimental 
tests). This is the opposite of the pattern predicted by a frontal-limbic account (Tarter, 1975), and the mixed allocentric task results, as measures of right parietal function, provide conflicting evidence regarding the right-hemisphere hypothesis.

The above studies (Beatty et al., 1997; Beatty et al., 1996; Ellis, 1990) illustrate how experimental tests of cognitive function can supplement standard clinical neuropsychological evaluation of neurobehavioral deficits in alcoholism and aging. Clinical tests have been used widely in alcoholism research because they sensitively reveal patterns of impairment and sparing across many overlapping and contrasting functional domains by engaging multiple perceptual, cognitive, and response-related functions. To enhance specificity, tests developed by cognitive psychologists can often serve as critical additions to the investigative arsenal in alcoholism research. Among these, the tasks that are especially informative are those employed in cognitive neuroscientific investigations to index a restricted set of brain functions. Besides being well suited for pinpointing the cognitive domains disrupted, they provide a functional neurobiological background against which a richer explanation of cognitive deficits in alcoholism (and aging) may be rendered. To further illustrate the role that such experimental tests play in alcoholism research, let us first take a closer look at the two types of experimental tests, mental rotation and imagery, that were used in the two studies by Beatty and colleagues $(1997 ; 1996)$ in the context of the egocentric versus allocentric space account.

\section{MENTAL ROTATION AND MENTAL IMAGERY}

In the mental rotation task used by Beatty et al. $(1997 ; 1996)$, people saw twodimensional (2-D) depictions of three-dimensional objects constructed of cubes. From four 2-D pictures, they chose the two depictions that, when rotated mentally, matched the target picture. For the mental imagery task people were required to report whether or not there were curves in the capitalized form of each lower case letter presented (Beatty et al., 1997; Beatty et al., 1996). While mental representations may be formed in both tasks, a spatial transformation of the representation is entailed by mental rotation but probably not by mental imagery.

For evaluation of the right-hemisphere account of alcoholism, these tasks were aptly pitted against each other. Mental rotation is dependent predominantly upon the right hemisphere, whereas mental imagery is dependent predominantly upon the left hemisphere. The specific brain areas activated during mental rotation of objects are inferior and superior parietal cortices and angular gyrus and some premotor areas in the frontal lobes (e.g., Kosslyn, DiGirolamo, Thompson, \& Alpert, 1998). These brain areas are distinct from those activated during mental imagery, namely, occipital, occipitotemporal, or inferior temporal cortices (Beatty et al., 1996; Corballis \& Sergent, 1989; D'Esposito et al., 1997; Ditunno \& Mann, 1990; Loverock \& Modigliani, 1995). Therefore, in addition to considering the righthemisphere hypothesis, the Beatty et al. studies also spoke to the effects of alcoholism on the anterior-posterior axis (and the dorsal-ventral dichotomy) (Mishkin, Ungerleider, \& Macko, 1983) of the brain. This is important because the frontal and parietal areas (i.e., anterior and dorsal) implicated in mental rotation have been found to be more compromised by alcoholism than the occipital and temporal areas (i.e., far posterior and ventral) implicated in mental imagery. Thus, 
impairments by alcoholics were expected on mental rotation but not on mental imagery tasks.

As expected, mental rotation performance was impaired in alcoholics compared to controls (Beatty et al., 1997; Beatty et al., 1996), confirming earlier findings (Glenn \& Parsons, 1991; Tarter, 1975). In contrast, mental imagery performance was similar between alcoholic and control groups in one study (Beatty et al., 1997) but not in the other (Beatty et al., 1996), although both studies showed the same small trend toward impairment. The latter tendency may reflect cognitive functions that are common to mental imagery and mental rotation tasks, with degree of involvement differing between tasks. For instance, the spatial analysis and/or attentional functions predominantly controlled by areas of the right parietal lobe may be more strongly engaged during mental rotation than mental imagery. Further, while there is evidence for hemispheric dominance in both tasks, there is also evidence of bilateral involvement in mental rotation and mental imagery (Kosslyn et al., 1998; Loverock \& Modigliani, 1995).

Regardless, the Beatty et al. (1997; 1996) findings indicate that the cognitive functions engaged predominantly during mental rotation (e.g., spatial transformation) are vulnerable to the effects of alcoholism, and they are more vulnerable than those engaged predominantly during mental imagery. If consistency across studies is taken as an indicator, the mental rotation and mental imagery results support the right-hemisphere account of alcoholism; they suggest that both right- and left-hemisphere functions (i.e., mental rotation and mental imagery processes, respectively) are compromised by alcoholism, but the right hemisphere is disproportionately impaired. This conclusion, however, depends upon the presumption of mental rotation as a right-hemisphere dominant task and mental imagery as left-hemisphere dominant, an idea that may not hold as evidence for bilateral involvement accumulates. Rather, the clearest finding of these studies is that alcoholism impairs visuospatial function more than some other visual functions, as indicated by the greater spatial demands of mental rotation over mental imagery.

While these tasks have not been used with alcoholic groups of different ages, there is research on how aging affects mental rotation and mental imagery. The studies suggest that there is impairment with increasing age. In particular, with aging, mental rotation accuracy decreases (e.g., Herman \& Bruce, 1983), and mental image activation and maintenance accuracy decrease (e.g., Dror \& Kosslyn, 1994). The impaired performance of alcoholics and elderly on both tasks (Herman \& Bruce, 1983) provides little support for the right-hemisphere hypothesis of alcoholism and aging.

\section{LATERALIZED CUED ATTENTION}

Another cognitive domain that is useful for evaluating the right-hemisphere hypothesis is that of attention, where the right hemisphere plays a specialized role (see for recent reviews Friedrich, Egly, Rafal, \& Beck, 1998; Heilman \& Valenstein, 1993; Ivry \& Robertson, 1998). In a recent study of visual attention, Evert and Oscar-Berman (submitted) measured the abilities of alcoholics and 
nonalcoholic controls between the ages of 29 years and 76 years to respond to targets processed by the two cerebral hemispheres. The methods they used were directly relevant to evaluating not only the right-hemisphere hypothesis but also the premature aging hypothesis. Moreover, lateralized presentation of the stimuli in the left and the right VFs further accentuated the ability of this study to evaluate the role of the right hemisphere in alcoholism and aging. Evert and Oscar-Berman (submitted) measured the effects of increased attentional demands in a visual cueddetection task, first, to establish right-hemispheric specialization in young healthy controls (under age 50) and then to assess right-hemispheric functional decline in the alcoholic and aging individuals. In the cued-detection task, a precue provided information about the most probable location of a subsequent target letter (i.e., in the left and the right VFs).

The young nonalcoholic controls showed a VF asymmetry. In particular, there was a specific disruption when an invalid cue was presented to the right VF (i.e., the left hemisphere), but the target appeared instead in the left VF (i.e., the right hemisphere). Thus, there was a right-hemisphere advantage in this task, since there was no disruption on trials where there were invalid cues to the Left VF and targets in the opposite VF. Unlike the younger controls, the alcoholics in both age groups (and the older nonalcoholic controls) showed no evidence of a right-hemisphere (left VF) advantage on the task; they were influenced by the validity of the cue regardless of the visual field where it appeared. In sum, the results from this experiment provided support for the accelerated aging model of premature aging and for the right-hemisphere models of alcoholism and aging.

\section{HIERARCHICAL PATTERN PERCEPTION AND ATTENTION}

While recent research with alcoholic participants using hierarchical stimuli is lacking (to our knowledge), there are recent findings from cognitive neuroscientific studies with healthy nonalcoholic people that elucidate earlier work on global versus local processing in alcoholics. In hierarchical visual patterns, a global shape is formed from the spatial configuration of many local elements (e.g., local level small triangles forming a global level square). Global-local tasks engage asymmetrically organized brain processes, with certain (global) functions carried out predominantly by the right hemisphere and other (local) functions carried out predominantly by the left hemisphere.

Evidence for this comes from studies such as that of Robertson and Delis (1986) who asked patients with lesions of the right or left hemisphere to make similarity judgments about hierarchical visual patterns. On each trial, a sample image (e.g., a square made of squares) was shown above two possible matching items. One item matched the form of the sample only at the global level (c.g., a square made of triangles), while the other matched only at the local level (e.g., a triangle made of squares). Patients with right-hemisphere lesions tended to choose the local match, whereas those with left-hemisphere lesions tended to choose the global match.

Using a similar paradigm, Kramer, Blusewicz, Robertson, and Preston (1989) found that alcoholics performed as predicted by the right-hemisphere hypothesis of alcoholism. Specifically, alcoholics chose the global match less often than 
nonalcoholic controls. The altered global bias of alcoholics reflected a quantitative rather than qualitative change because the influence of other variables, such as stimulus size and position, on hierarchical task perfornance was similar in alcoholics and controls. The degree of salieuce is thus reduced at the global level with chronic alcoholism, but the way hierarchical stimuli are processed seems to be similar in alcoholics and nonalcoholic controls. Interestingly, alcohol administered to young nonalcoholic people resulted in a global processing impairment resembling that seen in chronic alcoholics (Lamb \& Robertson, 1987).

A standard clinical neuropsychological test was also administered in the Kramer et al. (1989) study. On the WAIS-R Block Design subtest, alcoholics showed a higher incidence of configural errors relative to the controls. This finding is consistent with that from another study showing that configural errors on Block Design were similar for alcoholics and patients with circumscribed brain lesions in the right hemisphere (Akshoomoff, Delis, \& Kiefner, 1989). Thus, alcoholics appeared to have a right-hemisphere dysfunction of configural analysis. An advantage of Kramer et al.'s (1989) concurtent use of both clinical and experimental tests was that they could then perform correlational analyses on the two data pools. Block Design configural errors, however, were not significantly correlated with the increased local response bias on hierarchical stimuli. This suggests that, while both global processing of hierarchical images and Block Design configural errors may assess the efficiency of global level analysis, damage to somewhat distinct brain areas may be responsible for altered performance in each task. Indeed, other evidence suggests that either right parietal dysfunction or altered hemispheric dominance from callosal atrophy may affect performance on both tasks, whereas right frontal dysfunction (as in alcoholics) may be more important for errors on Block Design than for reduced global bias on hierarchical patterns (Chase, Fedio, Foster, et al., 1984; Kaplan, 1988; Pfefferbaum et al., 1996; Robertson, Lamb, \& Knight, 1988; Robertson, Lamb, \& Knight, 1991).

Findings from another experimental task with hierarchical stimuli were also consistent with the right-hemisphere hypothesis of alcoholism (Robertson, Stillman, \& Delis, 1985). In this case, a simple geometric figure was shown alone (e.g., a triangle) or in the context of other figures with the same form and orientation (e.g., three upright triangles in a row). On each trial, the orientation of the shape or row of shapes changed, and participants reported the orientation of the stimuli. When a figure was shown in context, its perceived orientation could change compared to when it was presented alone; in other words, the global context (the perceptual reference frame) alters the perceived orientation of the local elements. Alcoholics were found to be less influenced by the global context of the shapes than nonalcoholic controls. Specifically, with an isolated figure, controls and alcoholics showed a right alignment bias. In contrast, when a central figure was shown in the global context of two abutting figures, controls no longer showed the right-sided bias, whereas alcoholics continued to do so, as if they were ignoring the global reference frame.

While the premature aging hypothesis of alcoholism was not addressed in the Robertson et al. (1985) study, it was addressed in the Kramer et al. (1989) study but was not supported. There were no reliable correlations between age and eithet 
hierarchical task performance or Block Design configural errors in alcoholics or controls (Kramer et al., 1989), consistent with related research on Block Design (e.g., Libon et al., 1994). The null finding with aged nonalcoholic controls stands in contrast to a positive finding from another study that aging impairs memory for hierarchical stimuli (Akshoomoff, Delis, \& Haist, 1993). This impairment, however, affected memory for local but not global level information, running counter to the right-hemisphere hypothesis of aging. In particular, elderly people (ages 60 years to 78 years) recalled and recognized fewer local level forms than young ( 21 years to 39 years) or middle aged ( 44 years to 57 years) people, but aging did not affect memory for global form. Since the integrity of memory depends upon processing capacity, findings from both studies suggest that aging does not impair global level processing (Akshoomoff et al., 1993; Kramer et al., 1989). Further research, however, needs to assess processing capacity directly to determine whether local processing is instead compromised with aging.

Recent studies using neuropsychological, brain imaging (PET and functional MRI), and electrophysiological (e.g., event-related brain potential; ERP) techniques provide fine-grained neuroanatomical and temporal information regarding brain areas important for hierarchical pattern perception. Studies where a task is performed while measuring brain activity (with functional brain imaging or other brain sensing techniques) are especially important, as they provide the most direct way to link cognitive function (or dysfunction) in a brain region to behavioral task performance. Of course, direct links are also provided by neuropsychological studies where high resolution brain scans (e.g., MRI) reveal the loci of neural injury. For example, since patients with right or left prefrontal lesions perform normally on tasks with hierarchical stimuli, whereas those with right or left posterior lesions do not, anterior regions seem less important than posterior brain regions for attending to global and local levels of objects (Robertson \& Delis, 1986; Robertson et al., 1988; Robertson et al., 1991).

On a still finer scale, neuropsychological and brain imaging studies converge upon the superior-temporal gyrus and inferior parietal lobe as critical for analysis and selective attention of hierarchical patterns. Areas in the right hemisphere dominate global processing and those in the left hemisphere dominate local processing (Fink et al., 1996) (for review of neuropsychological studies see Robertson \& Lamb, 1991). Brain imaging studies (PET and fMRI) have also indicated that right and left ventral posterior visual cortices (i.e., inferior occipital and lingual gyri) are differentially modulated by globally versus locally directed perception. However, the hemispheric dominance is a top-down effect from the parietal lobe, and the direction of the hemispheric dominance depends upon the stimulus category. Specifically, in the ventral posterior region, the left (language) hemisphere analyzes local letter-like forms, whereas the right (visuospatial) hemisphere analyzes local objects. In contrast, the global forms (e.g., local teacups forming a global anchor) are analyzed by the corresponding region in the hemisphere opposite the one specializing in the local form (Fink et al., 1996; Fink et al., 1997; Martinez et al., 1997). The fine temporal information from ERPs combined with PET reveals that the hemispheric dominance of hierarchical pattern perception is primarily the consequence of later brain functions (after $260 \mathrm{msecs}$ ). This high-order processing is in the asymmetrically organized temporal-parietal 
region that controls visuospatial attention to global or local levels of objects (Heinze, Hinrichs, Scholz, Burchert, \& Mangun, 1998).

Recent cognitive neuroscientific findings thus provide a precise description of the neural systems responsible for patterns of hemispheric dominance with hierarchical visual patterns. This new knowledge, in turn, indicates that the altered patterns of performance with hierarchical patterns in alcoholic and aging individuals may principally reflect damage to the right parietal region, although callosal dysfunction is also a possibility. It should be noted that ventral posterior regions of the brain (i.e., the inferior occipital and lingual gyri) have not been implicated in alcohol-related brain damage as much as frontal brain systems (e.g., Pfefferbaum et al., 1997; Sullivan et al., 1998), and in at least one study, metabolic activity of posterior regions was normal (e.g., Volkow et al., 1997). Thus, posterior ventral regions are unlikely to be responsible for altered laterality patterns in alcoholics, based on current understanding from both cognitive neuroscientific investigations and neuroanatomical examination of alcoholic brain abnormalities.

A recently developed model of perceptual lateralization (double filtering by frequency theory or $D F F$ ) suggests that both hemispheres are important for global and local information processing but differ in how they analyze complex information (Ivry \& Robertson, 1998). In particular, the right hemisphere specializes in low frequency information, whereas the left hemisphere specializes in high frequency information. Thus, depending upon the spatial frequencies present in a visual image and whether they are the attended frequencies, either the right or left parietal lobe may be more important.

Based on this model from cognitive neuroscience, Ivry and Robertson (1998) recently offered two accounts of impaired global level performance from alcoholism. The first is consistent with the right-hemisphere hypothesis of alcoholism and suggests that disproportionate damage to the right hemisphere would disnupt the asymmetrically organized low spatial frequency filters therein. The second contradicts the right-hemisphere hypothesis of alcoholism and suggests that alcoholism would impair the functioning of left-hemisphere dominant systems that enable attention to switch from the local to global level.

Predictions from DFF theory, however, cannot be easily distinguished from those based on a competing model from cognitive neuroscience (Ivry \& Robertson, 1998). Consequently, Ivry and Robertson (1998) also suggested an account of alcoholism based on this other model, according to which the right hemisphere normally emits a wider spotlight of spatial attention than the left hemisphere. By this third account, alcohol may affect processes that determine the size of the attentional spotlight, reducing the region over which attention is spread. This may impair the ability of alcoholics to attend to and analyze the global level of hierarchical patterns (Brown \& Kosslyn, 1995). Evidence for this last account is the finding that intoxicated nonalcoholic individuals are better at detecting a foveal target but worse at detecting a peripheral target, as compared to sober controls. It is as if the attentional spotlight is focused narrowly on foveal information at the expense of peripheral coverage when people are under the influence of alcohol (Post, Lott, Maddock, \& Beede, 1996). Which of the above three accounts is best cannot be determined presently; one reason is that there is controversy surrounding 
whether a distinction can be made between (a) allocating attention to a spatial region of varying size (the spotlight account) versus (b) attending to different spatial resolutions (DFF theory).

\section{OTHER VISUAL TASKS}

There has been renewed interest in evaluating early sensory function in neurological populations with the recent emergence of well-honed techniques to do so. After all, certain aspects of visuospatial impairments could be a function of decreased early visual sensory functions rather than a function of visual cognition. Indeed, psychophysical evaluations have revealed that alcoholics show a reduction in visual contrast sensitivity over all spatial frequencies as compared to controls (Roquelaure et al., 1995). Consistent with this, alcohol intake reduces the contrast sensitivity function (Nicholson, Andre, Tyrrell, Wang, \& Leibowitz, 1995), suggesting that extensive alcohol intake (as in alcoholism) eventually produces long-lasting reductions in contrast sensitivity. Thus, early visual abnormalities may account for at least some of the behavioral impairments in alcoholism on visual tasks.

Indeed, recent cognitive neuroscientific investigations of early sensory processing in alcoholics indicates that this is the case. Damage to earlier sensory processing (before 150 msecs) may contribute to alcoholics' deficits in performance, if not to hemispheric asymmetry. Early visual, as well as auditory, ERPs seem to differ between alcoholic and control groups, with neurophysiological dysfunction indicated by ERP prolongation and size reduction (Nicolás et al., 1997). Further evidence for low-level damage is a decrease in estimated scalp surface energy observed by Cohen, Porjesz, Begleiter, and Wang (1997) while alcoholics performed a visual task at a time when extrastriate processing still fulfills primarily perceptual functions (Allison, McCarthy, Nobre, Puce, \& Belger, 1994; Heinze et al., 1998; Schendan, Ganis, \& Kutas, 1998).

Taken altogether, the preceding findings show fairly strong support for the idea that visual functions are abnormal in alcoholic and aging individuals. There are visual processing deficits from early sensory to later visuospatial cognitive processes, as assessed, for example, by spatial frequency, contrast sensitivity, and backward masking (see also, Oscar-Berman, Goodglass, \& Cherlow, 1973; Schlotterer, Moscovitch, \& Crapper-McLachlan, 1984). Still, the degree to which the abnormalities are tied to right-hemisphere dysfunction remains to be clarified.

Regardless, an important implication of abnormal visual functions in alcoholism and aging follows from the inherent relationship between processing and memory. The success of prior processing is an important factor in determining the efficacy of learning and memory encoding and retrieval (for discussion of this idea see a review by Miyashita, 1993). Once processing is sufficiently advanced, memory for the processed information can be encoded and related knowledge retrieved (e.g., Allan \& Rugg, 1997; Paller, Kutas, \& Mayes, 1987; Paller, Kutas, \& McIsaac, 1995; Schendan, 1998). It is thus likely that learning and memory for spatial information is impaired in alcoholics and the elderly.

A number of studies have explored the conditions under which alcoholics do and do not show normal spatial learning and memory, despite impaired visuospatial 
abilities. In contrast to their intact premorbid geographic memory, alcoholics are impaired on tests of memory for recently acquired spatial information, such as the New Map Test, where they learn and remember the locations of 15 imaginary cities in three fictional states (Beatty et al., 1997; Beatty et al., 1996). Aspects of maze learning and memory are also impaired by alcoholism. In a push-button maze task, alcoholics differed from the controls (Bowden \& McCarter, 1993). In that study, alcoholics failed to show equi-availability of spatial memory representations when learning and remembering shortcut movements, which were considered to depend upon explicit memory systems. In contrast, alcoholics and controls were equivalent in learning and remembering retrace movements that were considered to depend upon procedural memory, a component of implicit memory systems (i.e., memory without awareness) (for recent review see Schacter \& Buckner, 1998). Thus, alcoholics showed mildly impaired explicit (but not implicit) learning and memory for spatial information. It is noteworthy that, to some extent, deficits in spatial learning may reflect premorbid deficiencies in spatial learning. Evidence for this comes from the demonstration that visuospatial learning is also impaired in nonalcoholic individuals with a family history of alcoholism compared to those without such a family background (e.g., Garland, Parsons, \& Nixon, 1993).

At this point, it should be emphasized that alcoholics and healthy aging people have difficulty with memory for other materials besides visuospatial stimuli (Bates \& Convit, in press; Rourke \& Løberg, 1996). There are, for example, recent reports of impaired delayed explicit recall of both verbal and nonverbal materials in alcoholic and aging populations (e.g., Craik \& Jennings, 1992; Di Sclafani et al., 1995), although not all studies have shown deficits (e.g., Sullivan et al., 1995). In addition, chronic alcoholics and patients with left-hemisphere brain damage recalled less essential and detailed verbal material than patients with right-hemisphere brain damage (Tivis \& Parsons, 1997), a finding not consistent with the right-hemisphere hypothesis. However, alcoholics and left-hemisphere patients also were more depressed than the right-hemisphere patients (Tivis \& Parsons, 1997). Further, in another study with the same verbal memory tests, alcoholics did not differ reliably from controls when affective state was accounted for in the statistical analyses (Nixon, Hallford, \& Tivis, 1996). Clearly, additional research is needed to determine the pattern of memory deficits, especially since other factors (e.g., emotional abnormalities) may account for poor memory performance.

\section{ADDITIONAL FINDINGS FROM COGNITIVE NEUROSCIENCE}

One of the few techniques of cognitive neuroscience, namely ERPs, that has been applied to issues of neurobehavioral changes with alcoholism and aging has yielded evidence for changes in brain systems engaged late in information processing, besides the evidence for early sensory changes described earlier. For example, certain findings based on ERP examinations of alcoholic and aged brains are consistent with the idea that changes in brain regions involved in aftentional modulation that are activated late in processing (after 260 msecs) (Heinze et al., 1998) may be responsible for the visuospatial changes. The preponderance of ERP findings indicates that alcoholic brains differ neurophysiologically during later 
(after 300 msecs) cognitive processing (e.g., Cohen et al., 1997). The main electrophysiological marker of brain changes from alcoholism is the same one that prominently indexes brain changes in aging, that is, the $\mathrm{P} 300$ component. The size of the P300 is often found to be smaller in alcoholic and aged individuals than in control groups (e.g., Cohen et al., 1997; Polich, 1997; Porjesz et al., 1998).

More importantly for the right-hemisphere hypothesis, some studies report greater P300 reduction on the right than left side of the head. As a recent example, the results of a P300 study of visual perceptual fusion support the right-hemisphere hypothesis (Tsagareli, 1995). When the two parts of a whole geometric shape are rapidly and sequentially presented under conditions of backward masking, the parts can fuse perceptually to form a single shape. Using such a task, Tsagareli (1995) found that alcoholics discriminated the parts from the whole more slowly than control participants. In particular, alcoholics were slower to decide whether a complete and closed geometric figure had been shown, rather than two open fragments of geometric figures. What is more important is that alcoholics did not show the right-hemisphere advantage that controls demonstrated (i.e., with left VF presentation). This behavioral finding was mirrored in the P300 brain electrical potential, which was reduced in alcoholics, especially over the right hemisphere (Tsagareli, 1995). The late emergence of this effect indicates that the problem occurred at a high-order processing stage.

In a related study that emphasized working memory processes, ERPs after 250 msecs over right posterior scalp regions also differed between alcoholics and controls, with novel geometric figures that fit or did not fit to create a whole when conjoined with a preceding sample stimulus (Zhang, Begleiter, \& Porjesz, 1997). Working memory functions in the frontal lobes are thought to affect posterior processing, thereby influencing posterior activity. Therefore, vulnerable frontal neural systems that support working memory in alcoholics may exert an impaired influence on right posterior regions of the brains as well. Alternatively, posterior as well as frontal - neural systems may be impaired in alcoholics. The participants in these ERP studies were too young (mean ages 35 years or less) to evaluate the premature aging hypothesis. Regardless, this study indicates that short-term, working memory for visuospatial information is impaired in alcoholics. This finding also has implications for the issue of long-term memory impairment in alcoholism, given cognitive neuroscientific suggestions of a neuroanatomical link between short- and long-term memory functions (e.g., Gabrieli et al., 1996). Longterm memory for visuospatial information may thus result to some extent from impaired visuospatial working memory, as well as impaired visuospatial processing.

\section{MUSICAL, FACIAL, AND EMOTIONAL COGNITION}

Besides spatial cognition, other functions under control of the right hemisphere would be expected to be disrupted according to the right-hemisphere hypothesis of alcoholism. Among the functions with strong right-hemisphere involvement are musical, facial, and affective cognition. Note that while spatial cognition may be related to configural (or global) analysis of faces (Tanaka \& Farah, 1993), spatial ability (such as that measured by mental rotation) and emotion are not related (Crucian \& Berenbaum, 1998). 
As described earlier for music, Ellis (1990) found that dichotically presented tonal patterns were processed similarly by alcoholics and controls but not by patients with right-hemisphere lesions. By contrast, in another study of dichotic perception of melodies and words, Drake et al. (1990) found that alcoholic men did show evidence of right-hemisphere dysfunction: They had a significantly smaller left-ear superiority for melodies and a significantly larger right-ear superiority for words than controls.

Faces are another stimulus material that is dominated by right-hemisphere processing. Moreover, convergent findings in cognitive neuroscience indicate that right-hemisphere specialization for face stimuli takes place in low-level visual perceptual and higher-order semantic and other cognitive systems (e.g., Buckner, 1996; Damasio, Grabowski, Tranel, Hichwa, \& Damasio, 1996; Puce, Allison, Asgari, Gore, \& McCarthy, 1996). Thus, nearly any task with face stimuli should probe right-hemisphere dominant brain functions, making faces an especially crucial material for testing the right-hemisphere hypothesis of alcoholism and aging. Since cognitive neuroscientific evidence, however, implicates the right posterior ventral region in face perception (Puce et al., 1996), and there is a dearth of evidence for alcoholic brain damage specific to this region, impaired performance by alcoholics is unlikely on tasks that primarily tap early perceptual processing of faces in the posterior ventral region.

It is thus important that alcoholic performance on tasks with face stimuli have typically been assessed using higher-order cognitive tasks assessing explicit memory or emotion (e.g., Cermak et al., 1989; Oscar-Berman, Hancock, Mildworf, \& Hutner, 1990). For example, recent studies indicate that alcoholics are impaired at learning to attach names to the faces of unfamiliar people, a kind of cued recall task (Beatty et al., 1995; Tivis, Beatty, Nixon, \& Parsons, 1995). On face recognition tasks, however, alcoholic and control performance differs in some studies but not others. While alcoholic Korsakoff patients, who have long-term explicit memory impairments (for recent evidence see Oscar-Berman \& Pulaski, 1997), are deficient at perceiving and remembering the emotional information conveyed by faces, non-Korsakoff alcoholics are not (Oscar-Berman et al., 1990). Elderly individuals, however, regardless of alcohol history, perceived and remembered fewer emotional expressions in the faces than younger people (OscarBerman et al., 1990). Thus, neither the right-hemisphere nor the premature aging hypotheses of alcoholism was supported. In contrast, another study found that alcoholics correctly recognize fewer inverted faces than nonalcoholic controls (Nixon et al., 1996). Inverted faces, however, are thought be processed by posterior brain areas involved in object perception rather than those critical for face perception; only upright faces benefit from processing in brain areas specialized for face perception (Farah, Wilson, Drain, \& Tanaka, 1995). Thus, the impairment by alcoholics on recognition of inverted but not upright faces, suggests that the processing of objects, rather than face processing per se, may be impaired in alcoholism, and processing differences between upright versus misoriented face images probably are responsible for the poor memory. However, this study did not find the classic face inversion effect in the control group (where turning an image 
upside-down impairs face identification disproportionately more than for other objects) (Diamond \& Carey, 1986); hence, further research is needed.

Besides functional and neuroanatomical considerations, some of the inconsistency in the results from alcoholics can be explained by affective differences among research populations. For example, when affective properties (e.g., anxiety) were controlled, observed group effects on face recognition and other tasks, including visuospatial ones, were reduced or eliminated (Nixon et al., 1996). Therefore, at least some of the impaired performance of alcoholics on face recognition accuracy and response time may reflect affective characteristics, such as abnormal levels of anxiety, that often accompany alcoholism (Oscar-Berman, 1992; Oscar-Berman, 1998). For that reason, a comprehensive understanding of changes in emotional perception is a fruitful area of research, one that has largely been neglected. Further, the topic of emotional abnormalities in alcoholism and aging is important not just from the standpoint of contributions to cognitive functions (such as perceptual and attentional skills), but also because of the role of the right hemisphere in emotion.

Emotional abnormalities, such as those known to accompany alcoholism (McGue, Slutske, Taylor, \& Iacono, 1997; Oscar-Berman, 1992; Oscar-Berman et al., 1990), result from lesions in multiple brain systems (Borod, 1993; Gainotti, Caltagirone, \& Zocolotti, 1993; Heller, Nitschke, \& Miller, 1998). Modular models of emotion combine concepts from lateral dominance with ideas about corticalsubcortical interactions (Borod, 1993). Many brain centers act to take in emotional cues, evaluate them and execute appropriate reactions. Nonetheless, the right hemisphere's role in emotional functions generally is more relevant than the left's, and the right hemisphere (especially in the right frontal lobe) is more relevant for processing negative emotions than for positive emotions (for reviews, see Borod, 1993; Gainotti et al., 1993). Therefore, tasks that measure emotional functions (especially tasks that include stimuli with a negative valence) can be used to tap right-hemisphere abilities. If alcoholics have deficient right-hemisphere function, they should have more difficulty perceiving emotional materials than non-emotional materials. Moreover, among the emotional materials, alcoholics should have more difficulty perceiving negative than positive emotional stimuli. Likewise, if alcoholism interacts with aging, then deficits should be most pronounced in older alcoholics (compared with their nonalcoholic peers).

In a study of emotional functions in alcoholics in our laboratory, a visual backward-masking and perceptual laterality paradigm was used to assess emotional processing abilities in detoxified alcoholics compared to nonalcoholic controls ages 30 years to 69 years (Hunter \& Oscar-Berman, 1996). Emotional and nonemotional words were presented to the left or right VFs, followed by a visual masking stimulus. The research participants were asked to judge the emotional valence of each word (positive, negative, or neutral) and to respond verbally or manually (button presses). The dependent measure was the critical interstimulus interval needed to escape the backward-masking effect. The alcoholics showed a significant right VF (left-hemisphere) advantage in both response modes, whereas the controls did not. Furthermore, older alcoholics showed a selective impairment in processing negative words. Thus, when emotional materials were used, the 
findings supported the right-hemisphere model of alcoholism, as well as the increased vulnerability version of the premature aging hypothesis.

\section{SUMMARY AND CONCLUSIONS}

The right and left halves of the brain process sensory input and motor information differently. While the left hemisphere has a dominant role in linguistic behavior and the right hemisphere plays a dominant role in spatial cognition, the two hemispheres are complementary in their processing modes depending upon context and task demands. The left hemisphere plays a special role in processing piecemeal information analytically and sequentially, and the right hemisphere plays a special role in integrating information holistically. A common observation in work with alcoholics and with normal aging individuals is that both groups show lower scores on Performance IQ subtests (containing many visuospatial tasks) than on Verbal IQ subtests. From these observations, several hypotheses have emerged: (1) alcoholism may affect right-hemispheric functions more than left-hemispheric functions; (2) aging may affect right-hemispheric functions more than lefthemispheric functions; and (3) alcoholism may accelerate normal chronological aging. Research on cognitive capabilities and differences between the two cerebral hemispheres in alcoholics and in nonalcoholic aging individuals has provided limited support for the premature aging hypothesis and even less consistent support for the right-hemisphere hypothesis.

Since distinct functions and multiple brain areas can underlie different visuospatial tasks, broadly-defined neurobehavioral alterations can occur from injury to only a subset of visuospatial functions. Cognitive neuroscientific research has made notable progress in recent years with the advent of new functional brain imaging and sensing techniques and improvements to traditional approaches toward defining the functional contribution of specific brain systems to human behavior. These findings with populations of neurologically intact and impaired nonalcoholics, coupled with the neuroanatomical, neuropsychological, and cognitive neuroscientific studies of alcoholic and aged individuals, have provided additional means for more precisely testing the right-hemisphere hypothesis and the premature aging hypothesis. To date, the increased-vulnerability model of the premature aging hypothesis has received more support from imaging research than from neurobehavioral research. However, conclusive support still has not been forthcoming for either hypothesis. Nonetheless, with the new techniques available, we anticipate a successful future in understanding the ways the cerebral hemispheres act to integrate and complement their functions, as well as a similar leap in progress at pinpointing precisely the neurobehavioral consequences of longterm chronic alcoholism, normal chronological aging, and the synergism of alcoholism and aging.

\section{AKNOWLEDGMENTS}

The writing of this report was supported by NIAAA Grants R37-AA07112 and K05-AA00219 and by funds from the Medical Research Service of the US Department of Veterans Affairs. 


\section{REFERENCES}

Adams, K. M., Gilman, S., Johnson Greene, D., Koeppe, R. A., Junck, L., Kluin, K. J., Martorello, S., Johnson, M. J., Heumann, M., \& Hill, E. (1998). The significance of family history status in relation to neuropsychological test performance and cerebral glucose metabolism studied with positron emission tomography in older alcoholic patients. Alcoholism-Clinical and Experimental Research, $22(1), 105-110$.

Adams, K. M., Gilman, S., Koeppe, R. A., Kluin, K. J., Brunberg, J. A., Dede, D., Berent, S., \& Kroll, P. D. (1993). Neuropsychological deficits are correlated with frontal hypometabolism in positron emission tomography studies of older alcoholic patients. Alcoholism: Clinical and Experimental Research, 17 (2), 205-210.

Akshoomoff, N. A., Delis, D. C., \& Haist, F. (1993). Age-related changes in memory for visual hierarchical stimuli. Developmental Neuropsychology, 9 (3), 259-269.

Akshoomoff, N. A., Delis, D. C., \& Kiefner, M. G. (1989). Block constructions of chronic alcoholic and unilateral brain-damaged patients: A test of the right hemisphere vulnerability hypothesis of alcoholism. Archives of Clinical Neuropsychology, 4 (3), 275-281.

Allan, K. \& Rugg, M. D. (1997). An event-related potential study of explicit memory on tests of cued recall and recognition. Neuropsychologia, 35 (4), 387-397.

Allison, T., McCarthy, G., Nobre, A., Puce, A., \& Belger, A. (1994). Human extrastriate visual cortex and the perception of faces, words, numbers, and colors. Cerebral Cortex, 4 (5), 544-554

Banich, M. T. \& Heller, W. (1998). Evolving perspectives on lateralization of function. Current Directions in Psychological Science, 7 (1), 1-37.

Bates, M. E. \& Convit, A. (in press). Neuropsychology and neuroimaging of alcohol and illicit drug abuse. In A. Calev (Ed.), Neuropsychological functions in psychiatric disorders. Washington, D.C.: American Psychiatric Press.

Beatty, W. W., Blanco, C. R., Hames, K. A., \& Nixon, S. J. (1997). Spatial cognition in alcoholics: Influence of concurrent abuse of other drugs. Drug and Alcohol Dependence, 44, 167-174.

Beatty, W. W., Hames, K. A., Blanco, C. R., Nixon, S. J., \& Tivis, R. (1996). Visuospatial perception, construction and memory in alcoholism. Journal of Studies on Alcohol, 57 (2), 136-143.

Beatty, W. W., Katzung, V. M., Moreland, V. J., \& Nixon, S. J. (1995). Neuropsychological performance of recently abstinent alcoholics and cocaine abusers. Drug and Alcohol Dependence, 37, 247-253.

Belzunegui, T., Insausi, R., Ibanez, J., \& Gonzalo, L. M. (1995). Effect of chronic alcoholism on neuronal population in the mammillary body and the anterior thalamic complex of man. Histology and Hislopathology, $10(3), 633-638$.

Borod, J. C. (1993). Cerebral mechanisms underlying facial, prosodic, and lexical emotional expression: A review of neuropsychological studies and methodological issues. Neuropsychology, 7, 445-463.

Bowden, S. C. \& McCarter, R. J. (1993). Spatial memory in alcohol-dependent subjects: Using a pushbutton maze to test the principle of equiavailability. Brain and Cognition, 22 (1), $51-62$.

Brown, H. D. \& Kosslyn, S. M. (1995). Hemispheric differences in visual object processing: Structural versus allocation theories. In Davidson, R,J. \& Hugdahl, K (Eds.), Brain asymmetry (pp. 77-97). Cambridge, MA,: MIT Press.

Buckner, R. L. (1996). Beyond HERA: Contributions of specific prefrontal brain areas to long-term memory retrieval. Psychonomic Bulletin and Review, 3 (2), 149-158.

Cermak, L. S., Verfaellie, M., Letourneau, L., Blackford, S., Weiss, S., \& Numan, B. (1989). Verbal and nonverbal right hemisphere processing by chronic alcoholics. Alcoholism: Clinical and Experimental Research, 13 (5), 611-616.

Chase, T. N., Fedio, P., Foster, N. L., \& Al, E. (1984). Wechsler Adult Intelligence Scale performance. Cortical localization by fluorodeoxyglucose F18-positron emission tomography. Archives of Neurology, 41, 1244-1247.

Ciesielski, K. T., Waldorf, A. V., \& Jung, R. E., Jr. (1995). Anterior brain deficits in chronic alcoholism. Cause or effect? Journal of Nervous and Mental Disorders, 183 (12), 756-76!

Cohen, H. L., Porjesz, B., Begleiter, H., \& Wang, W. (1997). Neurophysiological correlates of response production and inhibition in alcoholics. Alcoholism: Clinical and Experimental Research, 2I (8), 1398-1406.

Corballis, M. C. \& Sergent, J. (1989). Hemispheric specialization for mental rotation. Cortex, 25 (1), 1525.

Courville, C. B. (1966). Effects of alcohol on the nervous system of man. Los Angeles: San Lucas Press. 
Craik, F. I. M. \& Jennings, J. M. (1992). Human memory. In F. I. M. Craik \& T. A. Salthouse (Eds.), The handbook of aging and cognition (pp. 51-110). Hillsdale, NJ: Lawrence Erlbaum Associates, Inc.

Crucian, G. P. \& Berenbaum, S. A. (1998). Sex differences in right hemisphere tasks. Brain and Cognition, 36, 377-389.

D'Esposito, M., Detre, J. A., Aguirre, G. K., Stallcup, M., Alsop, D. C., Tippet, L. J., \& Farah, M. J. (1997). A functional MRI study of mental image generation. Neuropsychologia, 35 (5), 725-730.

Damasio, H., Grabowski, T. J., Tranel, D., Hichwa, R. D., \& Damasio, A. R. (1996). A neural basis for lexical retrieval. Nature, 380 (6574), 499-505.

Davila, M. D., Shear, P. K., Lane, B., Sullivan, E. V., \& Pfefferbaum, A. (1994). Mammillary body and cerebellar shrinkage in chronic alcoholics: An MRI and neuropsychological study. Neuropsychology, 8, 433-444.

Di Sclafani, V., Ezekiel, F., Meyerhoff, D. J., Mackay, S., Dillon, W. P., Weiner, M. W., \& Fein, G. (1995). Brain atrophy and cognitive function in older abstinent alcoholic men. Alcololism: Clinical and Experimental Research, 19(5), 1121-1126.

Diamond, R. \& Carey, S. (1986). Why faces are and are not special: An effect of expertise. Journal of Experimental Psychology: General, 115, 107-117.

Ditunno, P. L. \& Mann, V. A. (1990). Right hemisphere specialization for mental rotation in normals and brain damaged subjects. Cortex, $26(2), 177-188$.

Drake, A. I., Hannay, H. J., \& Gam, J. (1990). Effects of chronic alcoholism on hemispheric functioning: An examination of gender differences for cognitive and dichotic listening tasks. Journal of Clinical and Experimental Neuropsychology, 12 (5), $781-797$.

Dror, J. E. \& Kosslyn, S. M. (1994). Mental imagery and aging. Psychology and Aging, 9 (1), 90-102.

Eichenbaum, H. (1997). Declarative memory: Insights from cognitive neurobiology. Annual Review of Psychology, 48, 547-572.

Ellis, R. J. (1990). Dichotic asymmetries in aging and alcoholic subjects. Alcoholism, Clinical and Experimental Research, /4 (6), 863-871.

Ellis, R. J. \& Oscar-Berman, M. (1989). Alcoholism, aging, and functional cerebral asymmetries. Psychology Bulletin, 106, 128-147.

Estruch, R., Nicolas, J. M., Salamero, M., Aragon, C., Sacanella, E., Fernandez-Sola, J., \& UrbanoMarquez, A. (1997). Atrophy of the corpus callosum in chronic alcoholism. Journal of Neurological Sciences, $146(2), 145-151$.

Evert, D. \& Oscar-Berman, M. (submitted). Selective attentional processing and the right hemisphere: Effects of alcoholism and aging. Neuropsychology.

Evert, D. L. \& Oscar-Berman, M. (1995). Alcohol-related cognitive impairments: An overview of how alcoholism may affect the workings of the brain. Alcohol Heallh and Research World, 19 (2), 89. 96.

Farah, M. J., Wilson, K. D., Drain, H. M., \& Tanaka, J. R. (1995). The inverted face inversion effect in prosopagnosia: Evidence for mandatory, face-specific perceplual mechanisms. Vision Researcl, 35 (14), 2089-2093.

Fink, G. R., Hailigan, P. W., Marshall, J. C., Frith, C. D., Frackowiak, R. S. J., \& Dolan, R. J. (1996). Where in the brain does visual attention select the forest and the trees? Nature, 382 (6592), 626628.

Fink, G. R., Marshall, J. C., Halligan, P. W., Frith, C. D., Frackowiak, R. S., \& Dolan, R. J. (1997). Hemispheric specialization for global and local processing: The effect of stimulus category. Proceedings of the Royal Society of London - Series B: Biological Sciences, 264 (1381), 487-494

Friedrich, F. J., Egly, R., Rafal, R. D., \& Beck, D. (1998). Spatial attention deficits in humans: a comparison of superior parietal and temporal-parietal junction lesions. Neuropsychology, 22 (2) 193-207.

Gabrieli, J. D. E., Desmond, J. E., Demb, J. B., Wagner, A. D., Stone, M. V., Vaidya, C. J., Keane, M. M., \& Glover, G. H. (1996). Functional magnetic resonance imaging of semantic memany processes in the frontal lobes. Psychological Science, 7 (5), 278-283.

Gainotti, G., Caltagirone, C., \& Zocolotti, P. (1993). Left/right and cortical/subcortical dichotomies in the neuropsychological study of human emotions. Cognition and Emotion, 7, $71-93$.

Garland, M. A., Parsons, O. A., \& Nixon, S. J. (1993). Visual-spatial learning in nonalcoholic young adults with and those without a family history of alcoholism. Journal of Studies on Alcohol, 54 (2), 219-224. 
Gilman, S., Adams, K. M., Johnsongreene, D., Kaeppe, R. A., Junck, L., Kluin, K. J., Martorello, S., Heumanı, N., \& Hill, E. (1996). Effects of disulfiram on positron emission tomography and neuropsychological studies in severe chronic alcoholism. Alcoholism - Clinical and Experimental Research, 20 (8), 1456-1461.

Glenn, S. W. \& Parsons, O. A. (1991). Effects of alcoholism and instructional conditions on speed/accuracy tradeoffs. Alcoholism: Clinical and Experimental Research, 15 (4), 612-619.

Harding, A. J., Wong, A., Svoboda, M., Kril, J. J., \& Halliday, G. M. (1997). Chronic alcohol consumption does not cause hippocampal neuron loss in humans. Hippocampus, 7 (10), 78-87.

Harper, C. (1998). The neuropathology of alcohol-specific brain damage, or does alcohol damage the brain? Journal of Neuropathology \& Experimental Neurology, 57 (2), 101-110.

Heilman, K. M. \& Valenstein, E. (1993). Clinical Neuropsychology ( $3^{\text {rd }}$ ed.). New York: Oxford University Press.

Heinze, H. J., Hinrichs, H., Scholz, M., Burchert, W., \& Mangun, G. R. (1998). Neural meachanisms of global and local processing: A combined PET and ERP study. Journal of Cognitive Neuroscience, IO (4), 485-498

Heller, W., Nitschke, J. B., \& Miller, G. A. (1998). Lateralization in emotion and emotional disorders. Current Directions in Psychological Science, 7 (1), 26-32.

Herman, J. F. \& Bruce, P. R. (1983). Adults' mental rotation of spatial information: Effects of age, sex and cerebral laterality. Experimental Aging Research, 9 (2), 83-85.

Hutner, N. \& Oscar Berman, M. (1996). Visual laterality patterns for the perception of emotional words in alcoholic and aging individuals. Journal of Studies on Alcohol, 57 (2), 144-154.

Ivry, R. B. \& Robertson, L. C. (1998). The two sides of perception. Cambridge, MA: MIT Press.

Jernigan, T. L., Butters, N., DiTraglia, G., Schafer, K., Smith, T., Irwin, M., Grant, I., Schuckit, M., \& Cermak, L. S. (1991). Reduced cerebral grey matter observed in alcoholics using magnctic resonance imaging. Alcoholism: Clinical and Experimental Research, 15 (3), 418-427.

Kaplan, E. (1988). A process approach to neuropsychological assessment. In T. Boll \& B. K. Bryant (Eds.), Clinical neuropsychology and brain function: Research, measurement, and practice (pp. 129-167). Washington, D. C.: American Psychological Association.

Kaplan, E., Fein, D., Morris, R., \& Delis, D. C. (1991). WAIS-R as a neuropsychological instrument. San Antonio, TX: The Psychological Corporation, Harcourt Brace Jovanovich, Inc.

Kaplan, E., Palmer, E. P., Weinstein, C., \& Baker, E. (1981). Block design: A brain-behavior based analysis. Paper presented at the Annual European Meeting of the International Neuropsychological Society, Bergen, Norway.

Kopelman, M. D. (1995). The Korsakoff syndrome. British Journal of Psychiatry, 166 (2), 154-173.

Kosslyn, S. M., DiGirolamo, G. J., Thompson, W. L., \& Alpcrt, N. M. (1998). Mental rotation of objects versus hands: Neural mechanisms revealed by positron emission tomography. Psychophysiology, $35(2), 151-161$.

Kramer, J. H., Bluscwicz, M. J., Robertson, L. C., \& Preston, K. (1989). Effects of chronic alcoholism on perception of hierarchical visual stimuli. Alcoholism: Clinical and Experimental Research, 13 (2), 240-245.

Kril, J. 3., Halliday, G. M., Svoboda, M. D., \& Cartwright, H. (1997). The cerebral cortex is damaged in chronic alcoholics. Neuroscience, 79 (4), 983-998.

Kwon, L. M., Rourke, S. B., \& Grant, I. (1997). Intermanual differences on motor and psychomotor tests in alcoholics: No evidence for selective right-hemisphere dysfunction. Perceptual and Motor Skills, $84(2), 403-414$.

Lamb, M. R. \& Robertson, L. C. (1987). The effect of acute alcohol on attention and the processing of hicrarchical patterns. Alcoholism: Clinical and Experimental Research, 11, 243-248.

Lezak, M. D. (1995). Neuropsychological assessment ( $3^{\text {rd }}$ ed.). Oxford: Blackwell Scientific Publications.

Libon, D. J., Glosser, G., Malamut, B. L., Kaplan, E., Goldberg, E., Swenson, R., \& Prouty Sands, L. (1994). Age, executive functions, and visuospatial functioning in healthy older adults. Neuropsychology, 8(1), 38-43.

Loverock, D. S. \& Modigliani, V. (1995). Visual imagery and the brain: A review. Journal of Mental Imagery, $19(1-2), 91-132$

Martinez, A., Moses, P., Frank, L., Buxton, R., Wong, E., \& Stiles, J. (1997). Hemispheric asymmetries in global and local processing: Evidence from fMRI. Neuroreport, 8(7), 1685-1689.

Mayes, A. R. (1995). Memory and amnesia. Behavioural Brain Research, 66 (1-2), 29-36. 
McGue, M., Slutske, W., Taylor, J., \& Iacono, W. G. (1997). Personality and substance use disorders: Effects of gender and alcoholism subtype. Alcoholism: Clinical and Experimental Research, 21 (3), 513-520

Milberg, W. P., Hebben, N., \& Kaplan, E. (1996). The Boston Process Approach to neuropsychological assessment. In l. Grant \& K. M. Adams (Eds.), Neuropsychological assessment of neuropsychiatric disorders ( ${ }^{\text {nd }}$ ed., pp. 58-80). New York: Oxford University Press.

Mishkin, M., Ungerleider, L. G., \& Macko, K. A. (1983). Object vision and spatial vision: Two cortical pathways. Trends in Neurosciences, $6(10), 414-417$.

Miyashita, Y. (1993). Inferior temporal cortex: Where visual perception meets memory. Annual Review of Neuroscience, 16, 245-263.

NIAAA. (1997). Ninth special report to the US Congress on alcohol and health. Bethesda, MD: NIAAA.

Nicholson, M. E., Andre, J. T., Tyrrell, R. A., Wang, M., \& Leibowitz, H. W. (1995). Effects of moderate dose alcohol on visual contrast sensitivity for stationary and moving targets. Journal of Studies on Alcohol, 56 (3), 261-266.

Nicolás, J. M., Catafau, A. M., Estruch, R., Lomeña, F. J., Salamero, M., Herranz, R., Monforte, R. Carderial, C., \& Urbano-Marquez, A. (1993). Regional cerebral blood flow-SPECT in chronic alcoholism: Relation to neuropsychological tesțing. Journal of Nuclear Medicine, 34 (9), 14521459

Nicolás, J. M., Estruch, R., Salamero, M., Orteu, N., Fernandez-Sola, J., Sacanella, E., \& UrbanoMarquez, A. (1997). Brain impairment in well-nourished chronic alcoholics is related to ethanol intake. Annals of Neurology, 41 (5), 590-598.

Nixon, S. J., Hallford, H. G., \& Tivis, R. (1996). Neurocognitive function in alcoholic, schizophrenic, and dually diagnosed patients. Psychiniry Research, 64, 35-45.

Oscar-Berman, M. (1992). The contribution of emotional and motivational abnormalities to cognitive deficits in alcoholism and aging. In L. Squire \& N. Butters (Eds.), Neuropsychology of memory $\left(2^{\text {nd }}\right.$ ed., pp. 81-94). New York: Guilford Press.

Oscar-Berman, M. (1998). Cognitive, behavioral, and structural deficits: Neuropsychological sequelue of chronic alcoholism. National Institute on Alcohol Abuse and Alcoholism neuroscience and behavior portfolio review of issues related to vulnerability, National Institute on Alcohol Abuse and Alcoholism, Washington, D. C.

Oscar-Berman, M., Goodglass, H., \& Cherlow, D. G. (1973). Perceptual laterality and iconic recognition of visual materials by Korsakoff patients and normal adults. Journal of Comparative and Physiological Psychology, 82 (2), 316-321.

Oscar-Berman, M., Hancock, M., Mildworf, B., \& Hutner, N. (1990). Emotional perception and memory in alcoholism and aging. Alcoholism: Clinical and Experimental Research, 14 (3), 383-393.

Oscar-Berman, M. \& Pulaski, J. L. (1997). Associative learning and recognition memory in alcoholi Korsakoff patients. Neuropsychology, $/ /$ (2), 282-289.

Paller, K. A., Kutas, M., \& Mayes, A. R. (1987). Neural correlates of encoding in an incidental leaming paradigm. Electroencephalography and Clinical Neurophysiology, 67 (4), 360-371.

Paller, K. A., Kutas, M., \& Mclsaac, H. K. (1995). Monitoring conscious recollection via the electrical activity of the brain. Psychological Science, 6(2), 107-111.

Parsons, O. (1987). Neuropsychological consequences of alcohol abuse: Many questions-some answers In O. Parsons, N. Butters, \& P. Nathan (Eds.), Neuropsychology of alcoholism (pp. 153-175). New York: Guilford Press.

Parsons, O. A. \& Nixon, S. J. (1993). Neurobehavioral sequelae of alcoholism. Behavioral Neurology, II (1), 205-218.

Pfefferbaum, A., Lim, K. O., Desmond, J. E., \& Sullivan, E. V. (1996). Thinning of the corpus callosim in older alcholic men: A magnetic resonance imaging study. Alcoholism: Clinical and Experimental_Research, 20 (4), 752-757.

Pfefferbaum, A. \& Rosenbloom, M. J. (1993). In vivo imaging of morphological brain alterations associated with alcoholism. In W. A. Hunt \& S. J. Nixon (Eds.), Alcohol-induced brain damage (Vol. 22, pp. 71-87). Rockville, MD: USDHHS, National Institutes of Health.

Pfcfferbaum, A., Sullivan, E. V., Mathalon, D. H., \& Lim, K. O. (1997). Frontal lobe volume las observed with magnetic resonance imaging in older chronic alcoholics. Alcoholism: Clinical ad Experimenial Research, 21 (3), 521-529.

Pfefferbaum, A., Sullivan, E. V., Rosenbloom, M. J., Shear, P. K., Mathalon, D. H., \& Lim, K O (1993). Increase in brain cerebrospinal fluid volume is greater in older than in younger alcohols patients: a replication study and CT/MRI comparison. Psychiary Research, 50 (4), 257-274. 
Polich, J. (1997). EEG and ERP assessment of normal aging. Electroencephalography and Clinical Neurophysiology, 104 (3), 244-256.

Porjesz, B., Begleiter, H., Reich, T., VanEerdewegh, P., Edenberg, H. J., Foroud, T., Goate, A., Litke, A., Chorlian, D. B., Stimus, A., Rice, J., Blangero, J., Almasy, L., Sorbell, J., Bauer, L. O., Kuperman, S., O' Connor, S. J, \& Rohrbaugh, J. (1998). Amplitude of visual P3 event-related potential as a phenotypic marker for a predisposition to alcoholism: Preliminary results from the COGA project. Alcoholism: Clinical and Experimental Research, 22 (6), 1317-1323.

Post, R. B., Lott, L. A., Maddock, R. J., \& Beede, J. I. (1996). An effect of alcohol on the distribution of spatial attention. Journal of Studies on Alcohol, 57, 260-266.

Puce, A., Allison, T., Asgari, M., Gore, J. C., \& McCarthy, G. (1996). Differential sensitivity of human visual cortex to faces, letterstrings, and textures: A functional magnetic resonance imaging study. Journal of Neuroscience, 16 (16), 5205-5215.

Reitan, R. M. \& Davison, L. A. (Eds.). (1974). Clinical neuropsychology: Current status and applications. Washington, D. C.: V. H. Winston \& Sons.

Robertson, L. C. \& Delis, D. C. (1986). "Part-whole" processing in unilateral brain-damaged patients: Dysfunction of hierarchical organization. Neuropsychologia, 24 (3), 363-370.

Robertson, L. C. \& Lamb, M. R. (1991). Neuropsychological contributions to theories of part/whole organization. Cognitive Psychology, 23 (2), 299-330.

Robertson, L. C., Lamb, M. R., \& Knight, R. T. (1988). Effects of lesions of temporal-parietal junction on perceptual and attentional processing in humans. Journal of Neuroscience, 8 (10), 3757-3769.

Robertson, L. C., Lamb, M. R., \& Knight, R. T. (1991). Normal global-local analysis in patients with dorsolateral frontal lobe lesions. Neuropsychologia, 29 (10), 959-967.

Robertson, L. C., Stillman, R., \& Delis, D. C. (1985). The effect of alcohol abuse on perceptual reference frames. Neuropsychologia, 23 (1), 69-76.

Roquelaure, Y., Le Gargasson, J. F., Kupper, S., Girre, C., Hispard, E., \& Dally, S. (1995). Alcohol consumption and visual contrast sensitivity. Alcohol and Alcoholism, 30 (5), 681-685.

Rourke, S. B. \& Løberg, T. (1996). The neurobehavioral correlates of alcoholism. In I. Grant \& S. J. Nixon (Eds.), Neuropsychological assessment of neuropsychiatric disorders ( $2^{\text {nd }}$ ed., pp. 423-485). New York: Oxford University Press.

Schacter, D. L. \& Buckner, R. L. (1998). Priming and the brain. Neuron, 20 (2), 185-195.

Schendan, H. E. (1998). The timecourse of activation of the neural operations and representations supporting visual object identification and memory. Unpublished doctoral dissertation, University of Califomia, San Diego, La Jolla, CA.

Schendan, H. E., Ganis, G., \& Kutas, M. (1998). Neurophysiological evidence for visual perceptual categorization of words and faces within $150 \mathrm{~ms}$. Psychophysiology, 35, 240-25l.

Schlotterer, G., Moscovitch, M., \& Crapper-McLachlan, D. (1984). Visual processing deficits as asessed by spatial frequency, contrast sensitivity and backward masking in normal ageing and Alzheimer's disease. Brain, 107, 309-325.

Shear, P. K., Sullivan, E. V., Lane, B., \& Pfefferbaum, A. (1996). Mammillary body and cerebellar shrinkage in chronic alcoholics with and without amnesia. Alcoholism: Clinical and Experimental Research, 20 (8), 1489-1495.

Sullivan, E. V., Deshmukh, A., Desmond, J. E., Shear, P. K., Lim, K. O., \& Pfefferbaum, A. (1996). Volumetric MRI analysis of cerebellar hemispheres and vermis in chronic alcoholics: Relationship to ataxia (abs). Journal of the International Neuropsychological Society, 2, 34.

Sullivan, E. V., Marsh, L., Mathalon, D. H., Lim, K. O., \& Pfefferbaum, A. (1995). Anterior hippocampal volume deficits in nonamnesic, aging chronic alcoholics. Alcoholism: Clinical and Experimental Research, 19(1), 110-122.

Sullivan, E. V., Mathalon, D. H., Lim, K. O., Marsh, L., \& Pfefferbaum, A. (1998). Patterns of regional cortical dysmorphology distinguishing schizophrenia and chronic alcoholism. Biological Psychiatry, 43 (2), 118-131.

Sullivan, E. V., Rosenbloom, M. J., \& Pfefferbaum, A. (1998). Brain vulnerability to alcoholism: Evidence from neuroimaging studies. National Institute on Alcohol Abuse and Alcoholism neuroscience and behavior portfolio review of issues related to vulnerability, National Institute on Alcohol Abuse and Alcoholism, Washington, D. C.

Tanaka, J. W. \& Farah, M. J. (1993). Parts and wholes in face recognition. Quarterly Journal of Experimental Psychology: Human Experimental Psychology, 46A (2), 225-245.

Tarter, R. E. (1975). Psychosocial deficit in chronic alcoholics: A review. International Journal of Addition, 10,327-368. 
Tivis, L. J. \& Parsons, O. A. (1997). Assessment of prose recall performance in chronic alcoholics: Recall of essential versus detail propositions. Journal of Clinical Psychology, 53 (3), 233-242.

Tivis, R., Beatty, W. W., Nixon, S. J., \& Parsons, O. A. (1995). Patterns of cognitivc impairment among alcoholics: Are there subtypes? Alcoholism: Clinical and Experimental Research, 19 (2), 496-500.

Tsagareli, M. G. (1995). The interhemispheric functional organization of human visuo-spatial perception. Neuroreport, 6 (6), 925-928.

Volkow, N. D., Hitzemann, R., Wang, G. J., Fowler, J. S., Burr, G., Pascani, K., Dewey, S. L., \& Wolf, A. P. (1995). Monitoring the brain's response to alcohol with positron emission tomography. Alcohol Health and Research World, 19, 296-299.

Volkow, N. D., Wang, G. J., Overall, J. E., Hitzemann, R., Fowler, J. S., Pappas, N., Frecska, E., \& Piscani, K. (1997). Regional brain metabolic response to lorazepam in alcoholics during early and late alcohol detoxification. Alcoholisn: Clinical and Experimental Research, 21 (7), 1278-1284.

Wang, G. J., Volkow, N. D., Roquc, C. T., Cestaro, V. L., Hitzemann, R. J., Cantos, E. L., Levy, A. V., \& Dhawan, A. P. (1993). Functional importance of ventricular enlargement and cortical atrophy in healthy subjects and alcoholics as assessed with PET, MR imaging, and neuropsychologic testing. Radiology, 186 (1), 59-65

Wechsler, D. (1981). Wechsler Adult Intelligence Scale-Revised: Manual. New York: The Psychological Corporation.

Wechsler, D. (1997). WAIS-III and WMS-III Technical Manual (3'd ed.). San Antonio, TX: Harcourl Brace \& Company.

Wcchsler, D. \& Stone, C. P. (1945). Wechsler Memory Scale. New York: The Psychological Corporation.

Zhang, X. L., Begleiter, H., \& Porjesz, B. (1997). Is working memory intact in alcoholics? An ERP study. Psychiatry Research, 75 (2), 75-89. 